\title{
ARTIGO
}

do https://doi.org/10.22481/praxisedu.v15i35.5679

\section{PERCEPÇÃO DOS PROFESSORES DE EDUCAÇÃO ESPECIAL ACERCA DO PLANO NACIONAL E DOS PLANOS MUNICIPAIS DE EDUCAÇÃO}

\author{
PERCEPTION OF TEACHERS OF SPECIAL EDUCATION ABOUT THE NATIONAL \\ PLAN AND MUNICIPAL EDUCATION PLANS
}

\author{
PERCEPCIÓN DE MAESTROS DE EDUCACIÓN ESPECIAL SOBRE EL PLAN \\ NACIONAL Y LOS PLANES DE EDUCACIÓN MUNICIPAL
}

\author{
Osni Oliveira Noberto da Silva \\ Universidade do Estado da Bahia - Brasil \\ Theresinha Guimarães Miranda \\ Universidade Federal da Bahia - Brasil \\ Miguel Angel Garcia Bordas \\ Universidade Federal da Bahia - Brasil
}

\begin{abstract}
Resumo: O objetivo do presente artigo foi analisar a compreensão dos professores de Atendimento Educacional Especializado (AEE), acerca do conhecimento sobre o Plano Nacional de Educação (PNE) e do Plano Municipal de Educação (PME) de seu respectivo município. O recorte do estudo apresentado neste artigo foi construído através de uma pesquisa quantitativa, em que se usou como instrumento de coleta de dados um questionário com perguntas fechadas e de múltipla escolha, focando na compreensão dos professores de AEE dos nove municípios da região do Piemonte da Diamantina, estado da Bahia. Os dados levantados indicaram que a maioria dos professores conhecem o Plano Nacional de Educação de ouvir falar, mas não conhecem as metas e estratégias apresentadas no referido documento. Já no que diz respeito aos Planos Municipais de Educação, mais professores afirmaram conhecer o Plano de seu respectivo município e também suas metas e estratégias. Entretanto, quase metade afirmaram não ter participado da construção deste documento. Uma maior participação dos docentes na construção das políticas públicas da localidade onde atuam é de extrema importância, haja vista que são eles que conhecem mais intimamente os problemas e entraves que por ventura possam existir em sua prática cotidiana. Além disso, muito dos cumprimentos de metas previstas, tanto no Plano Nacional quanto nos Planos Municipais, recaem sobre a responsabilidade dos docentes. Assim, é importante que mais estudos possam ser realizados, inclusive em outros municípios, estados e até diferentes regiões do país, a fim de criar aporte teórico e empírico acerca do tema aqui discutido.
\end{abstract}

Palavras-chave: Educação Especial; Plano Nacional de Educação; Plano Municipal de Educação 
Abstract: The aim of this paper was to analyze the understanding of teachers of Specialized Educational Attendance (AEE), about the knowledge about the National Education Plan (PNE) and the Municipal Education Plan (PME) of their respective municipality. The study cutout presented in this article was constructed through a quantitative research, which used as a data collection instrument a questionnaire with closed and multiple choice questions, focusing on the understanding of the ESA teachers from the nine municipalities of the Piedmont region. Diamantina, state of Bahia. The data collected indicated that most teachers know the National Education Plan to hear about, but do not know the goals and strategies presented in that document. Regarding the Municipal Education Plans, more teachers said they knew the Plan of their respective municipality and also its goals and strategies. However, almost half said they did not participate in the construction of this document. A greater participation of teachers in the construction of public policies of the locality where they work is extremely important, given that they are the ones who know most intimately the problems and obstacles that may exist in their daily practice. In addition, much of the achievement of targets set in both the National Plan and Municipal Plans rests with the responsibility of teachers. Thus, it is important that more studies can be carried out, including in other municipalities, states and even different regions of the country, in order to create theoretical and empirical support on the topic discussed here.

Keyword: Special Education; National Education Plan; Municipal Education Plan

Resumen: El objetivo de este artículo fue analizar la comprensión de los docentes de Asistencia Educativa Especializada (AEE), sobre el conocimiento sobre el Plan Nacional de Educación (PNE) y el Plan de Educación Municipal (PME) de su respectivo municipio. El recorte del estudio presentado en este artículo se construyó a través de una investigación cuantitativa, que utilizó como instrumento de recolección de datos un cuestionario con preguntas cerradas y de opción múltiple, centrándose en la comprensión de los maestros de la ESA de los nueve municipios de la región de Piamonte. Diamantina, estado de bahia. Los datos recopilados indicaron que la mayoría de los maestros conocen el Plan Nacional de Educación, pero no conocen las metas y estrategias presentadas en ese documento. Con respecto a los Planes de educación municipal, más docentes dijeron que conocían el Plan de sus respectivos municipios y también sus objetivos y estrategias. Sin embargo, casi la mitad dijo que no participó en la construcción de este documento. Una mayor participación de los docentes en la construcción de políticas públicas de la localidad donde trabajan es extremadamente importante, ya que son los que conocen más íntimamente los problemas y obstáculos que pueden existir en su práctica diaria. Además, gran parte del logro de los objetivos establecidos tanto en el Plan Nacional como en los Planes Municipales es responsabilidad de los docentes. Por lo tanto, es importante que se puedan realizar más estudios, incluso en otros municipios, estados e incluso diferentes regiones del país, con el fin de crear apoyo teórico y empírico sobre el tema que se trata aquí.

Palabra clave: Educación Especial; Plan Nacional de Educación; Plan de educacion municipal

\section{Introdução}

Este artigo é parte integrante de pesquisa de Doutorado, desenvolvida no Grupo de Estudos sobre Educação Inclusiva e Necessidades Educacionais Especiais (GEINE), do programa de Pós-graduação em Educação da Faculdade de Educação da Universidade Federal da Bahia (PPGE/FACED/UFBA). 
O tema do presente texto diz respeito a relação entre os professores de Educação Especial com o Plano Nacional de Educação do Brasil e os Planos Municipais de Educação, haja vista que estes documentos são elementos essenciais no que diz respeito aos rumos da educação.

O primeiro Plano Nacional de Educação (PNE) do Brasil foi publicado nos anos 60 do século XX, tendo como objetivo enfrentar os problemas educacionais do país e projetar, através de objetivos, metas e estratégias produzidas a partir de diagnostico realizados em várias áreas do campo educacional, melhoras gradativas a serem alcançadas em um determinado prazo, atualmente de dez anos.

O PNE serve assim como um documento norteador para o futuro. $\mathrm{O}$ atual em vigência foi homologado pela Lei Federal de 13.005 de 25 de junho de 2014 e tem sua validade até o ano de 2024. Ele leva em consideração as conquistas e fracassos do Plano anterior, apresenta um diagnóstico do que foi alcançado, dos desafios a serem enfrentados e projeta vinte grandes metas que são munidas de uma série de estratégias específicas importantes para o cumprimento de tais metas (BRASIL, 2014).

O documento é composto de 10 diretrizes e 20 metas que devem ser cumpridas através de estratégias específicas de cada tema e articulados com os Planos estaduais e municipais. As 10 diretrizes, contidas em seu artigo $2^{\circ}$ são:

I - erradicação do analfabetismo;

II - universalização do atendimento escolar;

III - superação das desigualdades educacionais, com ênfase na promoção da cidadania e na erradicação de todas as formas de discriminação;

IV - melhoria da qualidade da educação;

V - formação para o trabalho e para a cidadania, com ênfase nos valores morais e éticos em que se fundamenta a sociedade;

VI - promoção do princípio da gestão democrática da educação pública;

VII - promoção humanística, científica, cultural e tecnológica do país;

VIII - estabelecimento de meta de aplicação de recursos públicos em educação como proporção do Produto Interno Bruto (PIB), que assegure atendimento às necessidades de expansão, com padrão de qualidade e equidade;

IX - valorização dos(as) profissionais da educação;

$\mathrm{X}$ - promoção dos princípios do respeito aos direitos humanos, à diversidade e à sustentabilidade socioambiental (BRASIL, 2014. p. 43).

Uma das grandes virtudes do PNE é possibilitar a articulação entre o governo federal com as outras esferas do poder público, no caso os governos estaduais e principalmente os municipais, que são a base para que o PNE seja cumprido em sua integralidade, como explicado por Vicente e seus colaboradores (2015). 
O Plano Nacional de Educação (PNE), que exprime a política nacional da educação, com contribuições dos estados e municípios, dos profissionais da área e dos segmentos majoritários da população organizada, tende a dar reciprocidade ao trabalho de todas as instâncias públicas, evitando o desacerto entre as administrações públicas, nos campos federal, estadual, distrital e municipal (VICENTE, et al, 2015, pág. 225).

No que diz respeito ao tema específico referente ao trabalho na Educação Especial, o Plano Nacional de Educação atualmente em vigência fica concentrado principalmente na sua meta de número 4 , transcrito a seguir:

universalizar, para a população de quatro a dezessete anos com deficiência, transtornos globais do desenvolvimento e altas habilidades ou superdotação, o acesso à educação básica e ao atendimento educacional especializado, preferencialmente na rede regular de ensino, com a garantia de sistema educacional inclusivo, de salas de recursos multifuncionais, classes, escolas ou serviços especializados, públicos ou conveniados (BRASIL, 2014, p. 55).

Seguindo as demandas trazidas pelo Plano Nacional de Educação, a Secretaria de Educação do Estado da Bahia homologou através da Lei Estadual no 13.599 de 11 de maio de 2016 o Plano Estadual de Educação (PEE), também com vigência de dez anos. Nesse documento a Educação Especial também está representada na meta 4, transcrita a seguir:

Meta 4: Universalizar, para a população de 04 (quatro) a 17 (dezessete) anos com deficiência, transtornos globais do desenvolvimento e altas habilidades, o acesso à Educação Básica e ao atendimento educacional especializado, nas redes regulares de ensino, com a garantia de sistema educacional inclusivo, de salas de recursos multifuncionais, classes, escolas ou serviços especializados, públicos ou conveniados, até o último ano de vigência deste PEE-BA (BAHIA, 2016, pág. 16).

De acordo com Silva et al (2018a), o Plano Estadual de Educação da Bahia, em comparação com o Plano Nacional de Educação, dá a Educação Especial uma maior importância, já que a discussão desse tema não fica relegado apenas a Meta 4, mas também pulveriza o tema no decorrer de outros pontos no decorrer do texto:

Entretanto, ao contrário do Plano Nacional, o PEE traz a questão do cuidado com o aluno com deficiência, não só na meta 4, específica da Educação Especial, mas também no que se refere a Educação infantil (Meta 1), Do Ensino Fundamental (Meta 2), Da Alfabetização infantil (Meta 5), Da Educação Integral (Meta 6), Do aprendizado adequado na idade certa (Meta 
7), Da Educação Superior (Meta 12), Da Pós-Graduação (Meta 14), Da formação de professores (Meta 15), Da formação continuada (Meta 16) (SILVA et al, 2018, pág. 69).

Ainda que o PNE e o PEE da Bahia estejam alinhados em suas metas e objetivos, é importante que esse alinhamento também exista entre o Plano Nacional e os Planos Municipais de Educação (SILVA et al, 2018a). Nascimento et al (2017) também ratifica tanto a importância dos Planos Educacionais para o direcionamento das políticas públicas quanto a articulação entre eles para que tais políticas possam de fato serem materializadas:

O momento exige do poder público e da sociedade em geral, a perspectiva dos planos de educação, como elementos indispensáveis para o enfrentamento do apartheid educacional, consolidado até então por sistemas concorrentes, desarticulados e fragmentados. Retomar o sonho dos pioneiros, com a necessária atualização histórica que o momento exige, é uma utopia possível e necessária, especialmente quando se trata do planejamento da educação brasileira (p. 125).

Como já explicado, existe uma intima dependência entre os estados e municípios para o cumprimento das metas do PNE. Por conta disso cada município do Brasil precisou produzir seu próprio Plano Municipal de Educação (PME), também com validade de dez anos, trazendo principalmente um diagnóstico específico de sua realidade, inclusive com metas e objetivos próprios, mas com articulação direta com o PNE.

Essas articulações possibilitaram que fosse criado um caminho integrado para o desenvolvimento da educação brasileira, de maneira que fosse possível abarcar todas as peculiaridades, problemas, desafios próprios existentes entre os diferentes municípios e regiões do país (NASCIMENTO et al, 2017).

De modo a ajudar os municípios na organização e construção de seus próprios Planos Municipais de Educação, foi lançado pelo governo federal em 2014 um caderno de orientações em que apresenta o passo a passo, desde a apresentação e diagnostico do município, através de dados históricos e indicadores oficiais, a montagem do grupo de trabalho com representantes de vários setores da educação do município, construção das metas e estratégias, apresentação e discussão com a comunidade, tramitação na câmara e consequentemente aprovação e homologação pelo(a) prefeito(a) (BRASIL, 2014).

Um elemento importante é que o caderno de orientações reforça, entre outras coisas, a participação da comunidade e na construção coletiva do PME, haja vista se tratar de um plano 
decenal que atravessará diversas gestões municipais e assim deve ser encarado, como um plano do município e não da gestão vigente:

(...) é fundamental considerar que o PME deve ser do município, e não apenas da rede ou do sistema municipal. O Plano Municipal de Educação é de todos que moram no município; portanto, todas as necessidades educacionais do cidadão devem estar presentes no Plano, o que vai muito além das possibilidades de oferta educacional direta da Prefeitura. Também não se trata do plano de uma administração da Prefeitura ou da Secretaria Municipal de Educação, pois atravessa mandatos de vários prefeitos e dirigentes municipais de educação. $\mathrm{O}$ trabalho pressupõe o envolvimento das três esferas de gestão (federal, estadual e municipal) e de representações dos diversos segmentos da sociedade, mas não deixa de conferir peso e importância ao papel dos dirigentes municipais.

(...) O PME deve se articular aos demais instrumentos de planejamento. Os insumos necessários para a execução dos planos de educação terão de constar nos orçamentos da União e dos estados para que apoiem técnica e financeiramente os municípios ao longo da década. Na Prefeitura, instrumentos de planejamento terão de se vincular ao plano decenal de educação: Plano Plurianual (PPA), Lei de Diretrizes Orçamentárias (LDO), Lei Orçamentária Anual (LOA), Plano de Ações Articuladas (PAR), entre outros.

(...) Por fim, uma premissa indispensável de trabalho é o fato de que o PME tem de ter legitimidade para ter sucesso. Planos construídos em gabinetes ou por consultores alheios à realidade municipal tendem ao fracasso, mas um PME submetido ao amplo debate incorpora a riqueza das diferentes visões e vivências que a sociedade tem sobre a realidade que deseja alterar. Somente um Plano Municipal de Educação legítimo pode contar com o apoio de todos para monitorar seus resultados e impulsionar a sua concretização, através da mobilização da sociedade ao longo dos seus dez anos de vigência (BRASIL, 2014. Pág. 07).

Além disso o caderno de orientações possibilitou que houvesse relativa uniformidade nos Planos Municipais em sua forma, ainda que os elementos particulares de cada realidade estejam presentes em seu conteúdo, possibilitando a sintonia desejável e com o Plano Nacional, como explicado por Silva e Oliveira (2016):

Contudo, na ausência dos pressupostos necessários ao exercício desta autonomia, os documentos oficiais do Ministério da Educação passam a exercer forte influência no delineamento dos PME. Ao exigir, sob a óptica da cooperação entre os entes federados, o alinhamento dos planos municipais aos planos nacionais e, sincronicamente, estabelecer mecanismos de responsabilização, desconsiderando o que, de fato, coloca-se como competência dos municípios, o MEC abriu precedentes para que muitos gestores locais incluíssem nas metas dos PME estratégias que, na conjuntura legal existente no país, seriam de competência dos Estados e do Governo Federal, transformando estes precedentes em marcos legais municipais. (SILVA; OLIVEIRA, 2016. Pág. 118). 
É compreensível a atenção que a Educação Especial tem no PNE. Deste modo, a relação entre o Plano Nacional com os Planos Municipais de Educação (PME) são extremamente importantes para orientar as ações educacional pelos próximos 10 anos, sendo que o cumprimento das metas é responsabilidade de todas as instancias, como explicado por Aguiar (2010):

A avaliação do PNE evidencia que a ausência de cumprimento das metas não pode ser atribuída apenas à instância da União. Esta tem responsabilidades concretas, mas os estados, o Distrito Federal e os municípios são corresponsáveis pelos compromissos do Plano. Dependendo da forma como se efetivam as relações entre os entes federados, dos arranjos institucionais e das condições políticas existentes, as metas poderão ser ou não alcançadas. (AGUIAR, 2010, p. 724)

Seguindo a organização do Plano Nacional de Educação e as indicações do Caderno de Orientações, a Educação Especial foi inserida como uma meta nos PME em diversos municípios (geralmente a meta 4). Em alguns casos causou uma situação até inédita, haja vista que pela primeira vez os gestores municipais precisaram inicialmente montar um diagnóstico acerca da situação desse e dos outros temas referentes a educação de seus municípios, para só assim poderem montar suas metas e estratégias de forma mais fidedigna possível com a realidade existente em suas localidades.

Isso acabou expondo uma série de dificuldades latentes, tais como a falta de formação inicial e continuidade dos professores, problemas de estrutura física, pouco conhecimento acerca da quantidade de alunos com deficiência e/ou necessidades educacionais especiais no município, elementos que devem estar previstos nos planos municipais de educação (ARIOZA; TARTUCI, 2016).

Assim, como se tratam de elementos importantes no que diz respeito ao trabalho docente, é imperativo que os professores conheçam a fundo o PNE e além disso, tenham participado ativamente da construção do PME do seu respectivo município. Por conta disso, o objetivo desse artigo foi analisar a compreensão dos professores de AEE acerca do conhecimento sobre o Plano Nacional de Educação e do Plano Municipal de Educação de seu respectivo município.

\section{Metodologia}

O recorte do estudo apresentado neste artigo foi construído através de uma pesquisa quantitativa, em que foi utilizado como instrumento de coleta de dados um questionário 
composto de perguntas fechadas e de múltipla escolha, focando na compreensão dos professores de AEE, participantes do estudo, no que diz respeito a importância e conhecimento sobre o Plano Nacional de Educação e os respectivos Planos Municipais de Educação de suas cidades.

A vantagem de utilizar questionários se dá no fato de que a aplicação desse instrumento tem um custo reduzido para os pesquisadores, pode ser aplicado de forma relativamente rápida em uma grande quantidade de pessoas e poder analisar a opinião de grandes grupos sem precisar expor os indivíduos (GIL, 2010).

O lócus de pesquisa onde os dados foram coletados são os nove municípios que compõem o território de identidade do estado da Bahia, conhecido como Piemonte da Diamantina (Caém, Jacobina, Miguel Calmon, Mirangaba, Ourolândia, Saúde, Serrolândia, Umburanas e Várzea Nova). De acordo com informações do Instituto Brasileiro de Geografia e Estatística (IBGE) estes municípios agrupam uma população total de cerca de duzentos e setenta mil habitantes, sendo que $60,5 \%$ dos habitantes desse território moram na zona urbana (IBGE, 2017).

A partir de dados obtidos com as Secretarias Municipais de Educação de cada um dos municípios foi possível aferir que no ano de 2018 havia um total de 45 professores de Educação Especial que atuavam com Atendimento Educacional Especializado em escolas municipais do Piemonte da Diamantina. Depois da tentativa de contato inicial com os docentes selecionados, trinta e seis deles aceitaram participar do estudo, o que correspondeu a cerca de oitenta porcento dos sujeitos totais.

De acordo com o artigo segundo do Decreto presidencial $\mathrm{n}^{\circ} 7.611$, publicado em 17 de novembro de 2011, o Atendimento Educacional Especializado (AEE) é conceituado como sendo:

(...) o conjunto de atividades, recursos de acessibilidade e pedagógicos organizados institucional e continuamente, prestado das seguintes formas: I - complementar à formação dos estudantes com deficiência, transtornos globais do desenvolvimento, como apoio permanente e limitado no tempo e na frequência dos estudantes às salas de recursos multifuncionais; ou II suplementar à formação de estudantes com altas habilidades ou superdotação (BRASIL, 2011).

O AEE faz parte de uma série de garantias legais que foram regulamentadas através da Política Nacional de Educação Especial na perspectiva da Educação Inclusiva, que garantiu ao aluno com deficiência e/ou necessidades educacionais especiais o apoio educacional 
necessário para o seu desenvolvimento dentro da escola regular, através de uma atuação complementar ou suplementar (caso dos alunos com superdotação) e ocorrendo no turno oposto as aulas das sala de aula comum (BRASIL, 2008).

Respeitando os princípios éticos referentes a pesquisa utilizando seres humanos prescrito na Resolução 466/2012, que diz respeito a pesquisa em seres humanos e a Resolução 510/2016 que dispõe sobre as normas aplicáveis a pesquisas em Ciências Humanas e Sociais, o projeto ao qual este estudo foi derivado foi submetido ao Comitê de Ética da Universidade do Estado da Bahia (CEP/UNEB) sob número de protocolo CAAE: 79862917.6.0000.0057 e aprovado através do parecer $\mathrm{n}^{\circ} 2532.689$.

Além disso, apresentaram aos professores participantes um Termo de Consentimento Livre e Esclarecido (TCLE) que garante o consentimento para autorização do uso dos dados coletados para uso e publicação em textos acadêmicos, além de garantir o anonimato da identidade dos sujeitos participantes.

\section{Análise e discussão dos dados}

Todos os nove municípios pertencentes ao território do Piemonte da Diamantina possuem Planos Municipais de Educação em vigência. Esses documentos estão disponíveis através de acesso livre ao público no site "PNE em movimento", que é mantido pelo governo federal.

Todos os planos municipais possuem vigência de dez anos, sendo que nenhum teve o prazo finalizado durante a produção do presente estudo. Desses, apenas o plano municipal de Umburanas foi implementado anteriormente ao Plano Nacional de Educação atual e apenas o plano municipal de Miguel Calmon foi publicado após a vigência do Plano Estadual de Educação da Bahia.

O Plano municipal de Umburanas ${ }^{2}$ é o mais antigo em vigência, publicado em 2011; o plano de $\mathrm{Caém}^{3}$ foi publicado em 2014; os planos de Jacobina ${ }^{4}$, Mirangaba ${ }^{5}$, Ourolândia ${ }^{6}$,

\footnotetext{
${ }^{1}$ http://pne.mec.gov.br/planos-de-educacao/situacao-dos-planos-de-educacao.

${ }^{2}$ Lei municipal no 146 de 21/12/2011

${ }^{3}$ Lei municipal no 455 de 22/05/2014

${ }^{4}$ Lei municipal no 1333 de $19 / 09 / 2015$

${ }^{5}$ Lei municipal no 238 de 22/06/2015

${ }^{6}$ Lei municipal no 327 de $23 / 07 / 2015$
} 
Saúde $^{7}$, Serrolândia ${ }^{8}$ e Várzea Nova ${ }^{9}$ foram publicados em 2015; o plano mais novo é o de Miguel Calmon ${ }^{10}$, publicado no ano de 2017.

De acordo com Silva et al (2018b), ao analisar como as condições de trabalho dos professores que atuam com Educação Especial são tratados nos Planos Municipais de Educação nos municípios da região do Piemonte da Diamantina-Bahia, observaram que existe nos planos avaliados uma baixa cooperação entre os nove municípios da região, pois não existe nenhum elemento dos documentos que levem a compreensão de que eles pertencem ao mesmo território de identidade, apesar de que compartilhem de problemas comuns encontrados em todos os municípios investigados.

Entretanto, os Planos municipais também demonstraram possuir os elementos estruturais esperados, no que se refere ao diagnóstico da situação da Educação Especial nos próprios municípios e a apresentação de metas, cada uma com uma série de estratégias, com o objetivo de direcionar as políticas públicas educacionais dos municípios nos dez anos seguintes. E ainda:

A articulação entre o Plano Nacional e os Planos Municipais é visível. Ainda que não exista a garantia de que tudo que foi colocado como meta seja de fato materializado, os Planos servem inegavelmente como importantes instrumentos de diagnósticos e planejamento de ações para a melhoria da Educação de curto a médio prazo. (SILVA et al, 2018b. pág. 176).

Assim, levando em consideração que todos os municípios aqui discutidos possuem seus próprios planos e que eles direcionam as políticas públicas educacionais no período de dez anos, é importante que os professores participem ativamente das decisões e direcionamento que o município dá a educação, tanto no levantamento dos problemas existentes, quanto na cobrança e fiscalização dos gestores, além da participação ativa na construção da política educacional de seu município, o que demanda, entre outras coisas, a apropriação e conhecimento sobre a legislação vigente, tanto no âmbito nacional quanto local.

Por conta disso, o gráfico da figura 1 apresenta a compilação das respostas dos professores de Atendimento Educacional Especializado pesquisados têm acerca do Plano Nacional de Educação que está em vigência.

\footnotetext{
${ }^{7}$ Lei municipal $n^{\circ} 376$ de $25 / 06 / 2015$

${ }^{8}$ Lei municipal no 568 de 25/06/2015

${ }^{9}$ Lei municipal no 486 de 19/06/2015

${ }^{10}$ Lei municipal $n^{\circ} 586$ de $18 / 12 / 2017$
} 
Figura 1 - Conhecimento dos professores sobre o Plano Nacional de Educação Conhecimento dos professores sobre o Plano Nacional de Educação (2014-2024)

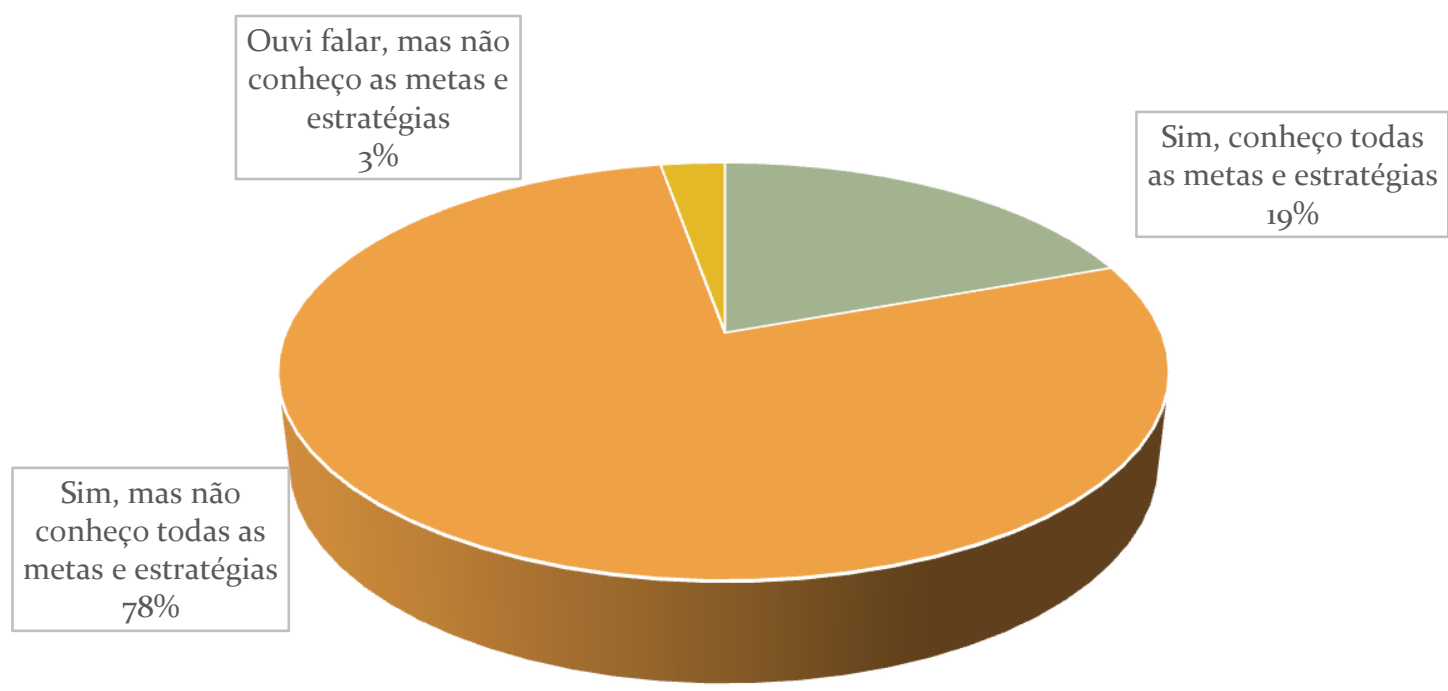

(Fonte: Elaboração própria, 2019)

Os dados deixam claro que $78 \%$ dos docentes afirmaram conhecer o Plano Nacional de Educação, mas não conhecem todas as metas e estratégias. Já 19\% afirmaram conhecer o PNE, inclusive conhecendo todas as metas e estratégias e apenas 3\% afirmaram ter ouvido falar do PNE. Em suma praticamente a totalidade dos docentes entrevistados conhecem o Plano Nacional de Educação atual.

No estudo de Albuquerque (2014) na rede pública municipal de ensino do Jaboatão dos Guararapes-PE foi observado que para os professores, apesar de conhecer a Lei de Diretrizes e Bases, a maioria desconhecia a Política Nacional de Educação Especial, excetuando aqueles que fizeram curso de Especialização na área.

Sobre a importância da abrangência e direcionamento que uma política pública educativa precisa ter, Emilio Fanfani (2007), em um estudo comparativo entre Argentina, Brasil, Peru e Uruguai sobre a condição de trabalho docente nesses países e chegou à conclusão que: 
El primer supuesto de política se puede formular de la siguiente manera: toda política docente debe ser integral. Esto quiere decir que debe contemplar intervenciones articuladas en por lo menos tres dimensiones: en el reclutamiento y la formación inicial y permanente, en las condiciones de trabajo (división del trabajo pedagógico, carrera, contexto institucional de trabajo, etc.) y en el sistema de estímulos y recompensas materiales y simbólicos (salario y reconocimiento social). Cualquier política que pretenda avanzar por un único andarivel está condenada al fracaso. Basta imaginar qué sucedería si se pretendiera sólo elevar las exigencias de la formación inicial sin modificar ni las condiciones de trabajo ni el salario ${ }^{11}$ (FANFANI, 2007, p. 280-281).

Concordando com este raciocínio, autores como Matos e Mendes (2014) reafirmam a importância da participação popular e também os educadores nas discussões necessárias para a materialização de políticas públicas no campo da Educação Especial. E ainda segundo os mesmos autores:

Discutir sobre as condições necessárias para se garantir o direito à educação da população atendida pela educação especial no país, hoje, significa refletir acerca da proposta de inclusão escolar desses alunos, mais especificamente sobre a política que induz à sua escolarização nas classes comuns das escolas regulares e sobre a realidade da atual política nacional de educação especial na perspectiva inclusiva (p. 37).

Levando em consideração que as metas e estratégias existentes no atual Plano Nacional devem estar intimamente relacionadas com os Planos municipais, acreditamos ser importante indagar os professores especificamente acerca do conhecimento que eles possuem sobre o PME de seu respectivo município. As respostas dos sujeitos foram compiladas e apresentadas no gráfico da figura 2.

\footnotetext{
${ }^{11}$ A primeira hipótese política pode ser formulada da seguinte forma: todas as políticas de ensino devem ser abrangentes. Isto significa que deve contemplar intervenções articuladas em pelo menos três dimensões: no recrutamento e na formação inicial e permanente, nas condições de trabalho (divisão do trabalho pedagógico, carreira, contexto de trabalho institucional, etc.) e no sistema. de estímulos e recompensas materiais e simbólicas (salário e reconhecimento social). Qualquer política que pretenda avançar através de uma única linha de vida está fadada ao fracasso. Basta imaginar o que aconteceria se pretendesse elevar os requisitos da formação inicial sem alterar nem as condições de trabalho nem o salário (Tradução nossa).
} 
Figura 2 - Conhecimento dos professores sobre o PME de seu respectivo município

\section{Conhecimento dos professores sobre o Plano Municipal de Educação}

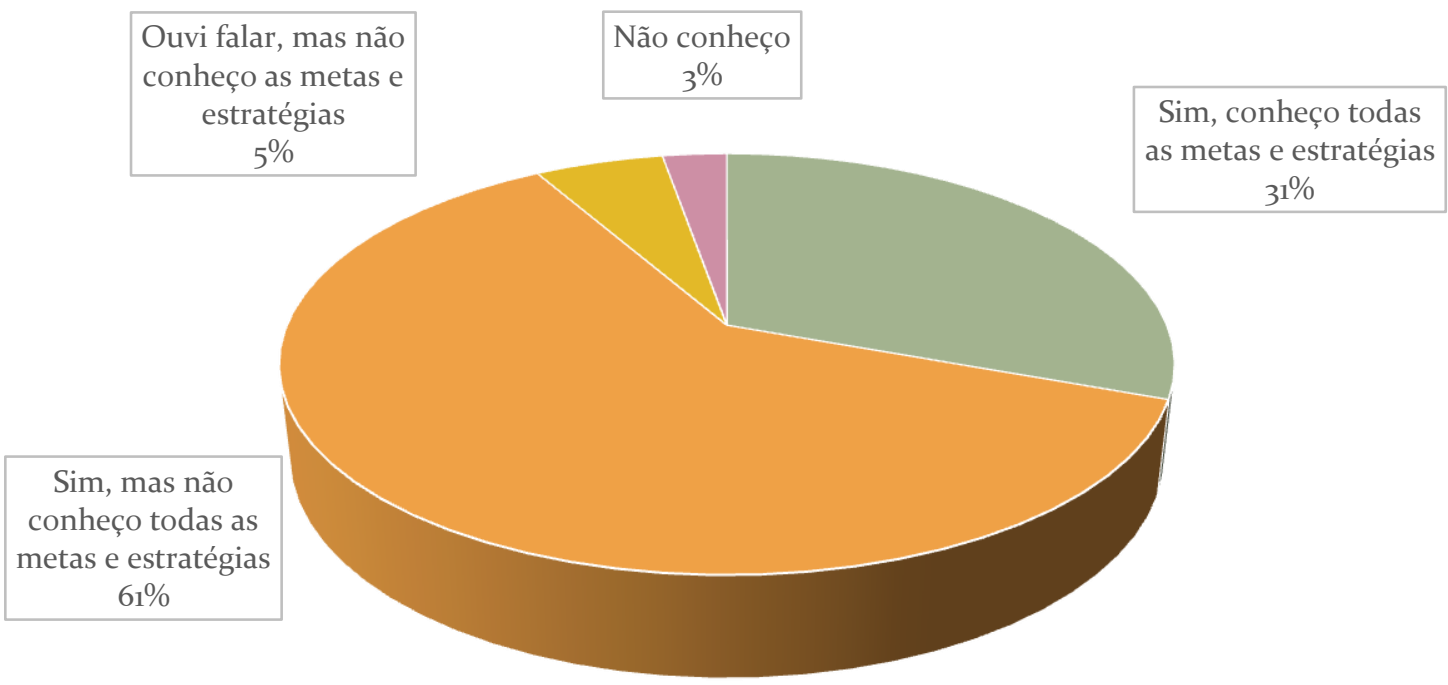

(Fonte: Elaboração própria, 2019)

$61 \%$ dos docentes disseram conhecer o PME do seu respectivo município, mas não conhecem todas as metas e estratégias. 31\% afirmam conhecer o Plano Municipal de Educação, inclusive conhecendo todas as metas e estratégias. 5\% afirmaram ouvir falar, mas não conhece as metas e estratégias e apenas 3\% afirmaram nunca ter ouvido falar sobre o PME do seu respectivo município.

Ainda dentro da questão do Plano Municipal de Educação, foi perguntado aos docentes se eles participaram da criação do PME de seu respectivo município e em caso afirmativo, como ele qualificaria essa participação dentro das seguintes opções: participação de forma satisfatória; participação de forma razoável; participação de forma discreta. 
Figura 3 - Participação da docente acerca da construção do PME de seu respectivo município Participou da construção do PME de seu municipio?

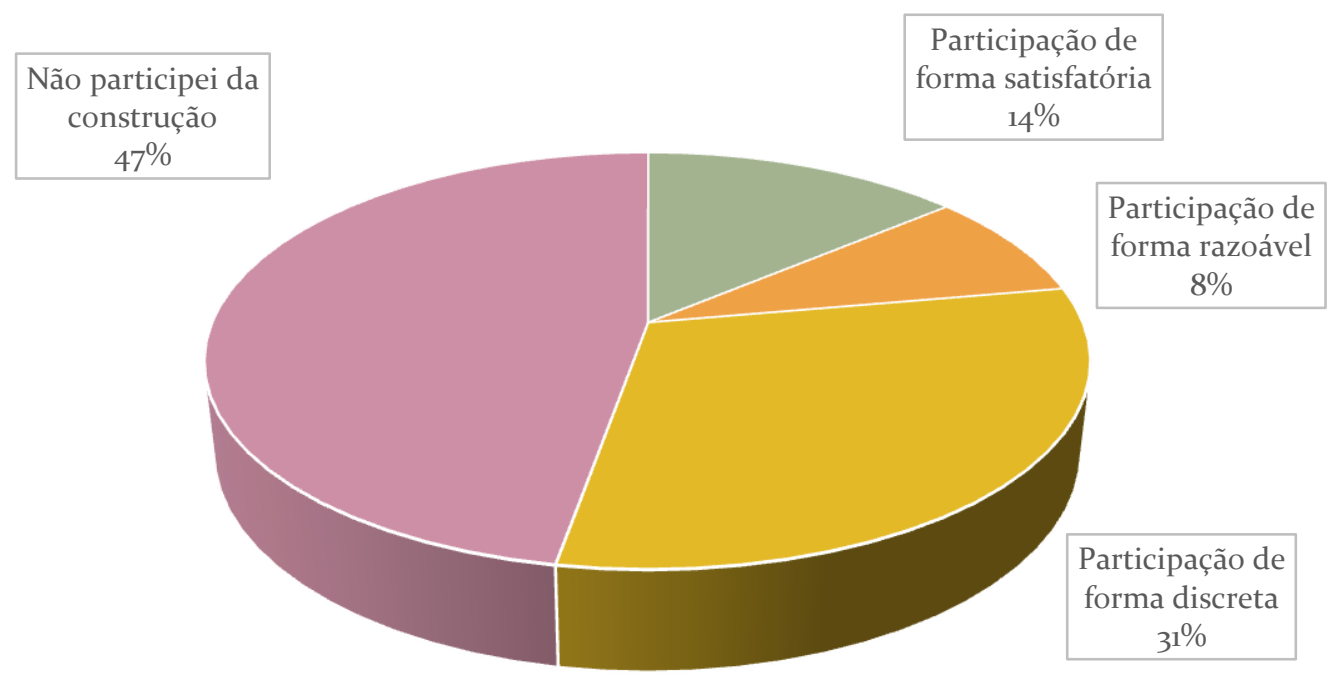

(Fonte: Elaboração própria, 2019)

Segundo os dados do gráfico da figura 3, 17 docentes ou $47 \%$ disseram que não participaram da construção do plano. Já 11 deles tiveram participação e a julgaram como tendo sido discreta, perfazendo $31 \%$ dos sujeitos. Para 5 docentes ou $14 \%$, a participação deles foi considerada de forma satisfatória e 3 professores consideraram a sua participaram na construção do PME como sendo razoável, o que correspondeu a 8\% dos sujeitos.

Os dados desse item são preocupantes, haja vista que apenas uma pequena parcela dos professores $(22 \%)$ disse ter participado ativamente, de forma satisfatória ou razoável, da produção do PME de seu município.

Isso porque acreditamos ser inegável a importância que os docentes têm na produção dos planos municipais de educação, tanto no que diz respeito ao diagnóstico, a produção dos objetivos e das metas, e até no acompanhamento e fiscalização do cumprimento do plano em sua totalidade, já que estão envolvidos diretamente nas ações e consequências que o plano trará para o seu município.

Assim, é temerário que exista tão baixa participação por parte dos professores, pois a “omissão permite que outros decidam por nós, e estas decisões provavelmente atendem aos 
interesses dos que decidem e não daqueles que delegam ou se omite de participar" (CÓSSIO, 2006, p. 31).

As tomadas de decisão coletiva e a gestão democrática são frutos das disputas pela redemocratização do país e materializadas na constituição de 1988 (MELO; DRAGO, 2015). Assim é provável que os atuais professores iniciaram suas carreiras na docência já dentro dessa concepção democrática e participativa.

Além disso, Nascimento e seus colaboradores (2017) alertam para o fato que ainda existem no Brasil "ranços" históricos que acabam emperrando o desenvolvimento educacional e social do país e que precisam ser enfrentados, através do direcionamento para uma unificação das políticas públicas de educação, principalmente num pais de características sui generis como o Brasil que ao mesmo tempo que dá uma autonomia relativa aos municípios, sinaliza a exigência de uma articulação e cooperação com as políticas públicas produzidas pelo governo federal.

\section{Considerações finais}

Aqui retomamos o objetivo do presente artigo, que foi analisar a compreensão dos docentes que atuam com Atendimento Educacional Especializado nos municípios do Piemonte da Diamantina, sobre o conhecimento acerca do Plano Nacional de Educação e do Plano Municipal de Educação do município onde atua.

Acreditamos que os dados coletados nesse estudo foram capazes de ajudar o objetivo do presente artigo ser cumprido, que foi analisar a compreensão dos professores de AEE acerca do conhecimento sobre o Plano Nacional de Educação e do Plano Municipal de Educação de seu respectivo município.

Os dados levantados indicaram que a maioria dos professores conhecem ou já ouviram falar do Plano Nacional de Educação, mas não conhecem as metas e estratégias apresentadas no referido documento.

Já no que diz respeito aos Planos Municipais de Educação, mais professores afirmaram conhecer o Plano de seu respectivo município e também a maioria de suas metas e estratégias. Entretanto, quase metade dos sujeitos afirmaram que não participaram da construção deste documento.

Uma maior participação dos docentes na construção das políticas públicas das localidades onde atuam é de extrema importância, haja vista que são eles que conhecem mais 
intimamente os problemas e entraves que por ventura possam existir em sua prática cotidiana na escola.

Além disso, muito dos cumprimentos de metas previstas, tanto no Plano Nacional quanto nos Planos Municipais, recaem sobre a responsabilidade dos docentes. Assim, é importante que mais estudos possam ser realizados, inclusive em outros municípios, estados e até diferentes regiões do país, a fim de criar aporte teórico e empírico robusto acerca do tema aqui discutido.

\section{REFERÊNCIAS}

AGUIAR, Márcia Ângela da Silva. Avaliação do Plano Nacional de Educação 2001-2009: questões para reflexão. Educação e Sociedade. Campinas, v. 31, n. 112, p. 707-727, jul./set. 2010.

ALBUQUERQUE, Ednea Rodrigues de. Prática pedagógica inclusiva: um estudo de caso em escola com atendimento educacional especializado (AEE) em Jaboatão dos GuararapesPE. 2014. 340 p. Tese (Doutorado em Educação). Universidade Federal de Pernambuco. Recife.

ARIOZA, Carolina dos Santos; TARTUCI, Dulcéria. Implantação da educação inclusiva na rede municipal de ensino de Catalão - GO e o trabalho do professor de apoio à inclusão: políticas, práticas e desafios. In: NEVES, Adriana Freitas; PAULA, Maria Helena de; ANJOS, Petrus Henrique Ribeiro dos (Org.). Estudos Interdisciplinares em Humanidades e Letras. Blucher. São Paulo: 2016.

BAHIA, Lei Estadual no 13.599, de 11 de maio de 2016. Aprova o Plano Estadual de Educação da Bahia e dá outras providências.

BRASIL. Lei no 13.005, de 25 de junho de 2014. Aprova o Plano Nacional de Educação (PNE) e dá outras providências.

BRASIL. Decreto $\mathbf{n}^{\mathbf{0}}$ 7.611/2011. Dispõe sobre a educação especial, o atendimento educacional especializado e dá outras providências.

\section{BRASIL. MEC/SEESP. Política Nacional da Educação Especial na Perspectiva da Educação Inclusiva, 2008.}

CÓSSIO, Maria de Fatima. Gestão democrática da educação: Retórica política ou prática possível. In: CAMARGO, Ieda de. (Org.). Gestão e políticas da educação. Santa Cruz: EDUNIS, 2006.

FANFANI, Emilio Tenti. La condicion docente: análisi comparado de la Argentina, Brasil, Perú y Uruguay. Buenos Aires: Siglo XXI Editores Argentina. 2007. 
GIL, Antônio Carlos. Como elaborar projetos de pesquisa. 5. ed. São Paulo: Atlas, 2010.

INSTITUTO BRASILEIRO DE GEOGRAFIA E ESTATÍSTICA/IBGE. Cidades. Em: http://www.cidades.ibge.gov.br/v3/cidades/home-cidades. Acessado em 5 de maio de 2019.

MATOS, Selma Norberto; MENDES, Enicéia Gonçalves. A proposta de inclusão escolar no contexto nacional de implementação das políticas educacionais. Práxis Educacional. v. 10, n. 16, jan./jun. 2014, p. 35-59.

MELO, Douglas Christian Ferrari de Melo; DRAGO, Rogério. Participação e gestão democrática na formação de professores. Laplage em Revista, vol.1, n.1, jan.- abr. 2015, p.36-45.

NASCIMENTO, Gilvânia da Conceição; GROSSI JUNIOR, Geraldo; PEREIRA, Jhonata Moreira. Planos municipais de educação - perfil dos municípios que não possuíam plano municipal de educação no segundo ano de vigência da lei n. 13.005/14. Revista Exitus. Santarém/PA, Vol. 7, N 1, p. 108-130, jan/abr 2017.

SILVA, Leandro Vitoriano da; OLIVEIRA, Maria Eliza Nogueira. O Plano Municipal de Educação: Da autonomia construída à autonomia decretada. Revista Teias, v. 17, n. 47, Out.Dez, 2016. Pág. $107-123$.

SILVA, Osni Oliveira Noberto da; MIRANDA, Theresinha Guimarães; BORDAS, Miguel Angel Garcia. O Atendimento Educacional Especializado no Plano Nacional de educacão do Brasil e no Plano Estadual de educacão da Bahia. Revista Pasajes, v. Jan-Jun, p. 62-76, 2018a.

SILVA, Osni Oliveira Noberto da; MIRANDA, Theresinha Guimarães; BORDAS, Miguel Angel Garcia. Análise das condições de trabalho na educação especial nos planos municipais de educação do interior da Bahia. Laplage em Revista, [S.1.], v. 4, n. 2, p. p.153-168, maio 2018 b.

VICENTE, Vinicius Renan Rigolin de; RAMOS, Carlos Vinícius; MOREIRA, Jani Alves da Silva. O financiamento da Educação Básica no Brasil: em discussão a vinculação de recursos. Revista tempos e espaços em Educação. Volume 8, Número 16 - maio/agosto 2015.

\section{SOBRE OS AUTORES}

\section{Osni Oliveira Noberto da Silva}

Doutorando em Educação pela Universidade Federal da Bahia (UFBA). Professor do Departamento de Ciências Humanas, Campus IV, da Universidade do Estado da Bahia (UNEB). Líder do Grupo de estudos, pesquisa e extensão em Educação Especial e Educação Física adaptada (GEPEFA) e integrante do Grupo de estudos sobre Educação Inclusiva e Necessidades Educacionais Especiais (GEINE). Bolsista do Programa de Apoio à Capacitação de Docentes da Uneb, PAC-DT. Email: osni_edfisica@ yahoo.com.br

(iD http://orcid.org/0000-0001-5028-0889 


\section{Theresinha Guimarães Miranda}

Doutora em Educação pela Universidade de São Paulo, com pós-doutorado pela Umeå University, Suécia. Professora do Programa de Pós-graduação em Educação da Universidade Federal da Bahia (UFBA). Integrante do Grupo de estudos sobre Educação Inclusiva e Necessidades Educacionais Especiais (GEINE). Email: tmiranda@ufba.br

(iD http://orcid.org/0000-0002-7762-7739

\section{Miguel Angel Garcia Bordas}

Doutor em Filosofia pela Universidad Complutense de Madrid, com pós-doutorado pela Universitat Autònoma de Barcelona, Espanha. Professor do Programa de Pós-graduação em Educação da Universidade Federal da Bahia (UFBA). Integrante do Grupo de estudos sobre Educação Inclusiva e Necessidades Educacionais Especiais (GEINE). Email: magbordas@gmail.com

\section{(iD) http://orcid.org/0000-0001-5970-9581}

Recebido em: 26 de julho de 2019 Aprovado em: 11 de agosto de 2019 Publicado em: 01 de outubro de 2019 